\title{
Solitary Rectal Ulcer with Anal "Seeds" Discharge after Transperineal Interstitial Brachytherapy for Prostate Cancer: A Case Report with Review of the Literature.
}

\author{
Fouad Aoun, Haydar A. Nasser, Roland van Velthoven and Alexandre Peltier
}

Institut Jules-Bordet, Brussels, Belgium.

Correspondence should be addressed to: Haydar A. Nasser; Derdyail@hotmail.com

Received date: 24 October 2013; Accepted date: 5 February 2014; Published date: 3 December 2015

Academic Editor: Stefano Carlo Maria Picozzi

Copyright (C) 2015. Fouad Aoun, Haydar A. Nasser, Roland van Velthoven and Alexandre Peltier. Distributed under Creative Commons CC-BY 4.0

\begin{abstract}
Brachytherapy was employed as curative treatment modality for localized prostate cancer early in the $20^{\text {th }}$ century. Transperineal implantation of prostatic radioactive seeds is generally safe, however serious complications may occur. Although the half -life of the ${ }^{125}$ is about 60 days, literature review showed that Solitary Rectal Ulcer tends to occur months to years after the initial treatment. We present a case of 72 year-old man, who complained of "seeds" anal discharge 7 years after prostate brachytherapy. Paraclinical investigations showed Solitary Ulcer of the Rectum with extra urethral prostatic-rectal fistula. Laparoscopic Loop colostomy was performed. The 4 months follow-up period was uneventful, and the symptoms had resolved. Currently the patient is awaiting colostomy reversal.
\end{abstract}

Keywords: Brachytherapy -Rectal Ulcer - Fistula

\section{Introduction}

Ultrasound-guided transperineal radioactive permanent seeds implantation is quickly growing in popularity as a treatment option for localized prostate cancer. Long term cancer control results are similar to outcomes observed after radical prostatectomy and external-beam radiation therapy (Orio 2012). However, prostate brachytherapy can lead to serious lifethreatening complications (Shah 2004). The most feared complication is rectal fistulae and the resulting need for colostomy. In contemporary series the rates of rectal fistula have been $<1 \%$ as stated by Orio (2012). We

Cite this Article as: Fouad Aoun, Haydar A. Nasser, Roland van Velthoven and Alexandre Peltier (2015),

"Solitary Rectal Ulcer with Anal "Seeds" Discharge after Transperineal Interstitial Brachytherapy for Prostate Cancer: A case report with review of the literature.", International Journal of Case Reports in Medicine , Vol. 2015 (2015), Article ID 356643, DOI: 10.5171/2015.356643 
present a unique case of extra-urethral rectoprostatic fistula with anal "seeds" discharge seven years post brachytherapy.

\section{Case Report}

A 70 year-old man, known to have COPD (Chronic Obstructive Pulmonary Disease), underwent permanent transperineal interstitial implantation of ${ }^{125}$ Iode, for a Gleason $3+3 \quad \mathrm{~T} 1 \mathrm{cN} 0 \mathrm{M} 0 \quad$ prostate adenocarcinoma, seven years ago $(19 / 9 / 2006)$. Noteworthy to mention, that the patient has had neoadjuvant cytoreductive hormonal ablation therapy before the brachytherapy which resulted in $35 \%$ decrease of the initial prostate volume. Though, before seeds implantation, the prostate was $35 \mathrm{cc}$ in volume, the measured serum PSA level was $7,72 \mathrm{ng} / \mathrm{ml}$ and International Prostate Symptom Score (IPSS) was 3 with a maximal flow rate of $17.7 \mathrm{ml} / \mathrm{s}$. The PSA level dropped to $0.03 \mathrm{ng} / \mathrm{ml}$ and then reached a plateau of $0.45 \mathrm{ng} / \mathrm{ml} 12$ months after the brachytherapy. During the seven year follow-up period, the patient was completely asymptomatic with a stable PSA. One month prior to his new admission, he suffered abnormal "seeds" discharge from the anus, copious mucus discharge, anal pain exacerbated with flatus and defecation and a feeling of incomplete defecation. No hematochesia, abnormal gastrointestinal transit, rectal bleeding or genitor-urinary symptoms and no rectal prolapse on physical examination were noted. The digital rectal examination revealed indurations on the anterior wall of the rectum. Flexible sigmoidoscopy was performed and revealed a large $(>2 \mathrm{~cm})$ cratered anterior wall solitary rectal ulcer just above the anorectal ring. The ulcer was surrounded by patchy friable erythematous lesions consistent with chronic proctitis and a fibrin dense reaction (figure.1). Endoscopic biopsy of these lesions showed areas of mucosal necrosis with thickwalled vessels and areas of dense fibrosis in the underlying connective tissue. The flexible cystoscopy revealed no abnormalities within the prostatic urethra. The pelvic MRI showed disruption of the anterior rectal wall, communicating with the extra-urethral prostatic space (figure. 2). Surgical consultation was obtained and the decision was made to perform a laparoscopic diverting loop colostomy since it was a grade 4 Radiation Therapy Oncology Group (RTOG) complications. Now the patient is on 4 month of follow-up post-colostomy; he has complete resolution of his symptoms. 


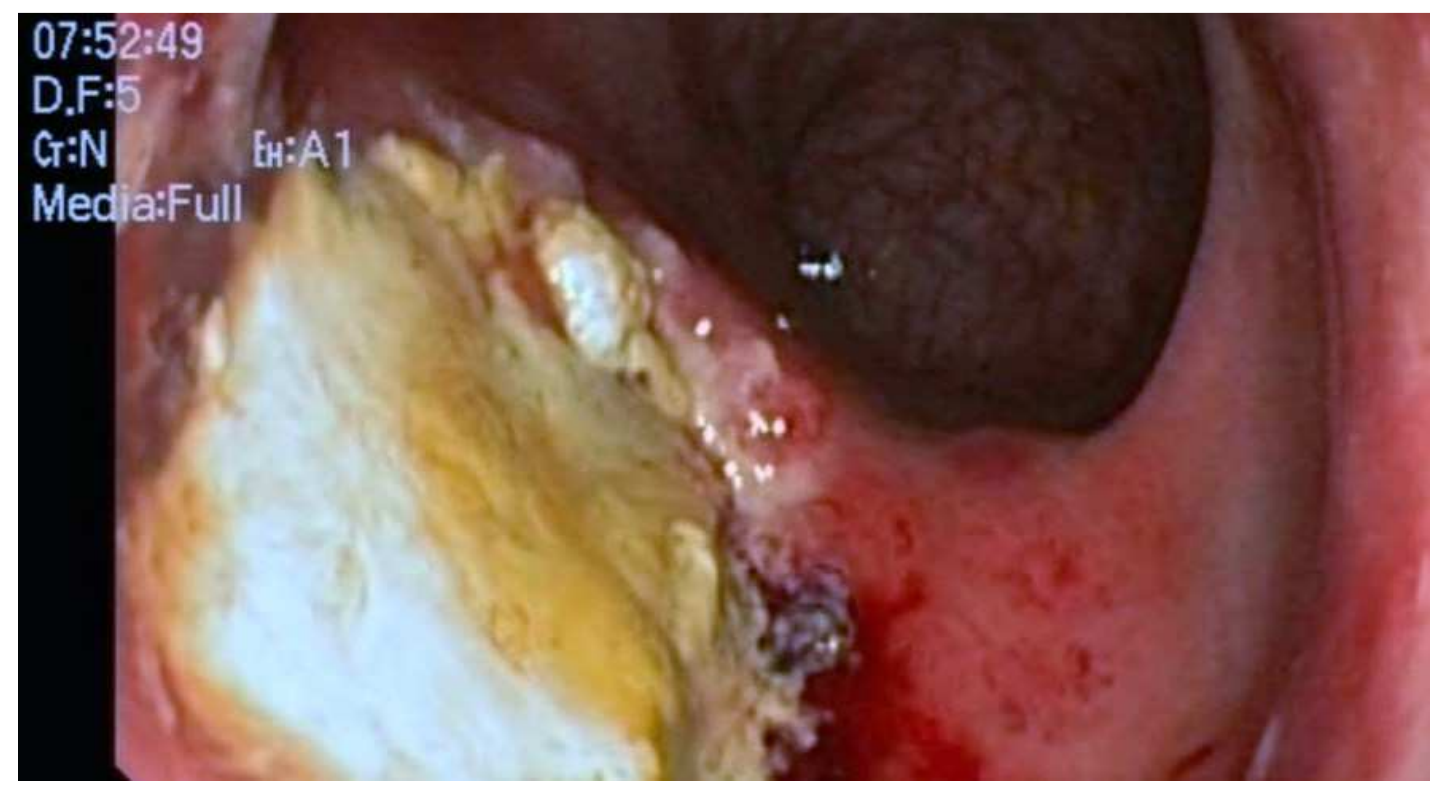

Figure 1: Colonoscopy Showing Anterior Rectal Ulcer with Inflammatory Reaction.

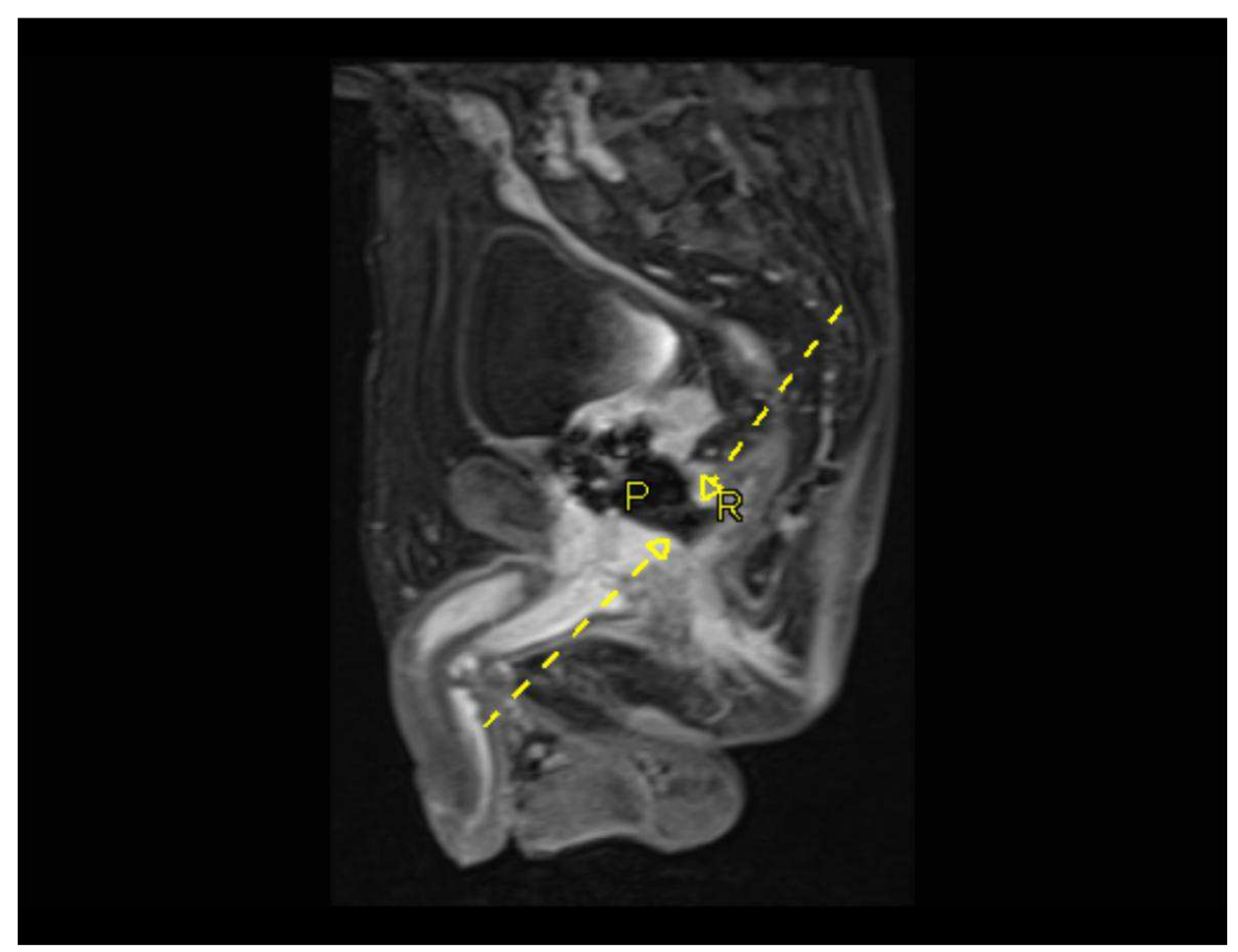

Figure 2: T1 Weighted Sagittal MRI Showing Complete Disruption Of The Anterior Wall of The Rectum. Both Dashed Yellow Arrows Indicate The Site Of The Fistula. $P=$ Prostate $R=$ Rectum

Fouad Aoun, Haydar A. Nasser, Roland van Velthoven and Alexandre Peltier (2015), International Journal of Case Reports in Medicine, DOI: 10.5171/2015.356643 


\section{Discussion}

Recent developments in radioactive seed implantation techniques have led to a significant increase in the use of brachytherapy as a standard treatment modality for localized prostate cancer. In contrast to acute rectal injury, chronic radiation toxicity are not only limited to mucosa but involves submucosal tissues with small vessels obliteration resulting in ischemia of the rectal wall. In almost all similar reported cases of urethra-rectal fistula [Davis(2001) ; Marguet (2007) ; Theodorescu (2000) ] in patients who have had perineal radioactive seeds implantation , rectal ulcer biopsy has preceded rectal fistula formation . Rectal complications are associated with age, external beam radiotherapy, high charlson comorbidity index, and inflammatory bowel disease as cited by Chen (2006). Prostate volume is not considered an associated risk factor; Kovtum et al (2013) demonstrated that the total radiation dose delivered to the rectum by day 30 post - brachytherapy, was nearly the same in small and large prostate groups. As it was stated by Litwin et al (1999), most of these patients are elderly and their symptoms could be related to a primary rectal dysfunction (e.g. malignancy). Thus in this particular group of patients, a screening colonoscopy would be advised before starting brachytherapy to avoid unnecessary biopsy in the setting of an eventual posttherapeutic complication. Apart ruling out adenocarcinoma, reveals unspecific chronic radiation changes as described by Brandt (2009).

Therapeutic options for rectal ulcers vary from supportive treatment to pelvic exenteration [Pham (2009), Moreira (2011)]. The best treatment is to avoid injury. None can predict the best treatment option, since these complications are becoming rare. The rate of complications has drastically decreased since 1990 as mentioned by chen et al (2006), and some authorities are trying to further minimize them. Robot assisted seeds implantation has been started in many institutions world-wide and results seem to be promising (Fichtinger 2008). A recent study done Ohashi et al (2007) showed that the total radiation dose , to the rectal wall, should not exceed 160 Gy in order to prevent severe complications.

To the best of our knowledge, our case is the first case where prostate-rectal fistula remained in the extra-urethral space and manifested as seeds discharge from the anus. Only one recent case report mentioned ulcer formation without subsequent fistulization, 16 months after brachytherapy (Brant 1999). Radiation ulcer is a bothersome problem both for the patient and the treating physician. The patient suffers chronic rectal pain not relieved by any position with the sensation of incomplete defecation, copious mucous discharge and hematochesia. This leads frequently to anemia, fatigue, depression and alteration in the quality of life. The physician is frustrated by the suboptimal therapeutic choices available in front of a demanding suffering patient and despite correct diagnosis, outcomes can be unsatisfactory. In the case of our patient, despite a complete resolution of symptoms after loop diverting colostomy, he was not satisfied since we have substituted his initial condition by another bothersome condition, which is colostomy. 


\section{References}

1. Brandt L.J (2009). Large solitary rectal ulcer as a complication of prostate brachytherapy. "Gastrointestinal endoscopy "70 : ( 2) 389-90.

2. Chen A.B , D'Amico A.V , Neville B.A, and Earle C.C (2006) "Patient and Treatment Factors Associated With Complications After Prostate Brachytherapy" JOURNAL OF CLINICAL ONCOLOGY 24:5298-5304.

3. Davis J.W and Schellhammer P.F (2001) "Prostatorectal Fistula 14 years following brachytherapy for prostate Cancer" THE JOURNAL OF UROLOGY 165: 189.

4. Fichtinger G, Fiene J.P , Kennedy C.W, Kronreif G, Iordachita I, Song D.Y, Burdette E.C , Kazanzides P. (2008) "Robotic assistance for ultrasoundguided prostate brachytherapy"Medical Image Analysis; 12: 535-545.

5. Kovtun K.A, Wolfsberger L, Niedermayr T, Sugar E.N, Graham P.L , MurcianoGoroff Y, Beard C, D'Amico A.V , Martin N.E , Orio P.F and Nguyen P.L (2013) "Dosimetric quality and evolution of edema after low-dose-rate brachytherapy for small prostates: Implications for the use of newer isotopes" Brachytherapy. (Article in press).

6. Litwin M.S (1999) "Health related quality of life in older men without prostate cancer" The Journal of Urology; 161: 1180-1184.

7. Marguet C, Raj G.V , Brashears J.H , Anscher M.S, Ludwig K, Mouraviev V, Robertson C.N, and Polascik T.J (2007)
"Rectourethral Fistula After Combination Radiotherapy for Prostate Cancer" UROLOGY 69: 898 -901.

8. MOREIRA S.G., SEIGNE J.D., ORDORICA R.C. , MARCET J., POW-SANG J.M. and LOCKHART J.L. (2003) "Devastating complications after brachytherapy in the treatment of prostate adenocarcinoma" B J U International 93: 31 - 35 .

9. Ohashi $\mathrm{T}$, Yorozu A, Toya K, Saito $\mathrm{S}$, Momma T, Nagata $H$ and Kosugi $M$ (2007) "Rectal Morbidity Following I125 Prostate Brachytherapy in Relation to Dosimetry" Jpn J Clin Oncol 37(2)121126

10. Orio P.F, Merrick G. S. Galbreath R.W, Butler W.M, Lief J, and Wallner K.E. (2012)." Patient-reported long-term rectal function after permanent interstitial brachytherapy for clinically localized prostate cancer." Brachytherapy 11:341-47.

11. Pham J, Swanson D.A, Levy L.B, Kudchadker R.J, Bruno T.L and Frank S.T (2009) "Late Rectal Complications after Prostate Brachytherapy for Localized Prostate Cancer" Cancer 115:1827-39.

12. Shah S.A , Cima R.R, Benoit E , Breen E.L, and Bleday R (2004) "Rectal Complications After Prostate Brachytherapy" Dis Colon Rectum 47: 1487-1492.

13. Theodorescu D, Gillenwater JY, and Koutrouvelis PG. (2000) "Prostatourethral-rectal fistula after prostate brachytherapy. "Cancer 89(10):2085-91. 